\title{
Sete Anos da Sociedade Brasileira de Atividade Física e Saúde: realizações, compromissos e ideais
}

Rev Bras Ativ Fis Saúde p. 527-528 DOI

http://dx.doi.org/10.12820/rbafs.v.19n5p527

Universidade Federal do Maranhão, Departamento de Educação Física, São LuísMA, Brasil

A Sociedade Brasileira de Atividade Física e Saúde (SBAFS) completou seu jubiloso sétimo aniversário em 16/11/2014. Comemorar os sete anos da SBAFS é uma honra e uma alegria para seus associados. Constatamos, com facilidade, que a trajetória de realizações da SBAFS é primorosa. Essa história, naturalmente, não poderia ter sido construída por poucos.

O pioneirismo dos fundadores (Adair da Silva Lopes, Airton José Rombaldi, Alex Antônio Florindo, Alexandre C Marques, Antônio C Cabral Oliveira, Antônio Eduardo Muzzi, Ciro R Rodriguez-Añez, Cynthia Maria Dutra, Dalton Grande, Dartagnan Pinto Guedes, Eloir E Simm, Erinaldo Luiz de Andrade, Felipe Ferreira da Costa, Felipe Fossati Reichert, Fernando C V Siqueira, Franscisco Godin Pitanga, Hector Luiz R Minaro, Iara Palmeira, José Cazuza de Farias Júnior, Juarez Vieira do Nascimento, Karla T A Simm, Katya Albano Salomão, Louise Farah Saliba, Marcelo Cozzensa da Silva, Marcelo Tessari, Maria Aparecido Venâncio, Maria Cecília M Tenório, Maria Fátima S Duarte, Maria Fermínia L De Bem, Maria R Tenório Mendonça, Mario Renato Azevedo, Markus Vinicius Nahas, Marlos R Domingues, Mathias Roberto Loch, Mauro Vírgílio G de Barros, Neiva Leite, Paola N Camacho Rojas, Pedro Rodrigues Curi Hallal, Rafael M Tassitano, Ricardo Alvez Mendes, Rodrigo Siqueira Reis, Rosane C Rosendo da Silva, Silvano Kruchelski, Silvio Aparecido Fonseca, Sisane Graup, Timóteo Leandro de Araújo e Valbério Candido de Araújo), a abnegação indistinta de todas as Diretorias executivas e, sobretudo a participação constante dos seus membros, tem mantido acesa a tradição de Sociedade coesa e sólida.

A SBAFS congrega estudantes, profissionais e pesquisadores de diversas áreas de formação com interesse no campo da atividade física e saúde, com abrangência em todo o território nacional. Nas realizações científicas, destaca-se a Revista Brasileira de Atividade Física e Saúde (RBAFS) periódico oficial que publica artigos veiculando os resultados de pesquisas e estudos sobre a temática da atividade física e saúde em diferentes subgrupos populacionais. A SBAFS, consciente de que deve e pode transcender sua função de órgão de divulgação e de publicação dos trabalhos científicos, conta com o apoio de grupos de pesquisas (Grupo de Estudos e Pesquisa em Epidemiologia da Atividade Física - GEPEAF da Universidade Federal da Paraíba liderado pelo Prof. Dr. José Cazuza de F. Junior; Grupo de Estudos e Pesquisas Epidemiológicas em Atividade Física e Saúde - GEPAF da Universidade de São Paulo Leste liderado pelo Prof. Dr. Alex Antonio Florindo; Grupo de Pesquisa em Epidemiologia da Atividade Física - GEEAF da Universidade Federal de Pelotas liderado pelo Prof. Dr. Pedro Hallal; Grupo de Pesquisa em Estilos de Vida e Saúde - GPES da Universidade de Pernambuco liderado pelo Prof. Dr. Mauro Virgilio Gomes de Barros e Prof. Dr. Rafael Miranda Tassitano; Núcleo de Pesquisa em Atividade Física e Qualidade de Vida - GPAQ da Pon- 
tifícia Universidade Católica do Paraná liderado pelo Prof. Dr. Rodrigo Reis; Núcleo de Pesquisa em Atividade Física e Saúde - NUPAF da Universidade Federal de Santa Catarina liderado pela Profa. Dra. Kelly Samara da Silva) e com o apoio da International Society for Physical Activity and Health - ISPAH.

Destaca-se ainda o Congresso Brasileiro de Atividade Física e Saúde (CBAFS) que desde 1997, bianualmente, vem disseminando conhecimentos produzidos na área da atividade física e saúde. São as ações somadas dos renomados profissionais envolvidos na dinâmica do processo que contribuem constantemente para a evolução da área de atividade física e saúde ${ }^{1}$. Não é necessário ir tão longe na história para ter a certeza de que ela é bonita, séria e deve ser motivo de orgulho para cada um de seus sócios, diante dos apontamentos dos importantes debates e questões levantadas ${ }^{2-5}$.

Estamos certos de que a SBAFS tem cumprido sua missão de maneira organizada, responsável e competente, consolidando ações de impacto e qualidade e construindo sempre um futuro de crescimento e novos desafios. Desejo aos prezados colegas da SBAFS muito sucesso e que os próximos anos continuem sendo marcados pelo êxito, com a realização de todos os sonhos sonhados. A SBAFS está de parabéns!

\section{REFERÊNCIAS}

1. Carvalho W. Para a pluralidade da atividade física e saúde é necessário sair da zona de conforto, ousar nas decisões. Rev Bras Ativ Fís Saúde. 2014;19:275-6.

2. Reis RS. Reflexões sobre o IX Congresso Brasileiro de Atividade Física e Saúde. Rev Bras Ativ Fis Saúde. 2013;18(5):521-2.

3. Florindo AA, Rombaldi AJ, Barros MVG. Análise da Revista Brasileira de Atividade Física e Saúde em 2013: O copo está meio-cheio ou meio vazio?. Rev Bras Ativ Fís Saúde. 2013;18:653-4.

4. Rombaldi, AJ, Florindo AA, Farias Júnior JC. Novidades da Revista Brasileira de Atividade Física e Saúde para 2014. Rev Bras Ativ Fís Saúde. 2014;19:1.

5. Reis RS, Loch M; Rech C, Hino A, Gonçalves P. A Caminhada da Sociedade Brasileira de Atividade Física e Saúde: percursos, tropeços e próximos passos. Rev Bras Ativ Fís Saúde. 2014;19:12.

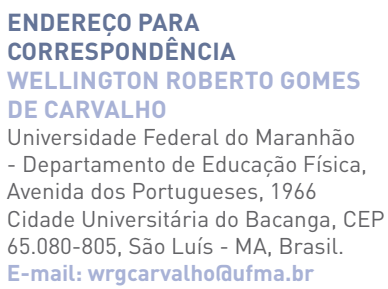

